\title{
EFEK DAUN SIRIH MERAH (Piper Crocatum) TERHADAP KADAR GULA DARAH DAN GAMBARAN MORFOLOGI ENDOKRIN PANKREAS TIKUS WISTAR (Rattus Norvegicus)
}

\author{
${ }^{1}$ Liestiono S. Nasi \\ ${ }^{2}$ Carla F. Kairupan \\ ${ }^{2}$ Poppy M. Lintong
}

\author{
${ }^{1}$ Kandidat Skripsi Fakultas Kedokteran Universitas Sam Ratulangi Manado \\ ${ }^{2}$ Bagian Patologi Anatomi Fakultas Kedokteran Universitas Sam Ratulangi Manado \\ Email:
}

\begin{abstract}
Leaves of 'sirih merah' (Piper Crocatum) contain compounds such as flavonoid, alkaloid and tannin, wich are capable of lowering blood sugar levels. This study aimed to investigate the effects of the administration of 'sirih merah' broth on blood sugar levels and histopathological features of pancreatic endocrine. This was a laboratory experimental study which was conducted for five month using 12 wistar rats as objects. The rats were divided into four groups: Group A (negative control), which received no treatment; group B, which were given the broth of 'sirih merah' at 2,4 ml; Group C, which were given sugar solution at 2,4 ml; and Group D, which were given the broth $(1,2 \mathrm{ml})$ and sugar solution $(1,2 \mathrm{ml})$. The results revealed that the levels of blood sugar decreased in rats in Groups B and D but increased in Group C. When compared with rats in Group A, the size and the number of Langerhans islets increased in Group C (more than twice). On the contrary, the number of Langerhans islets in Group D was relatively similar with that of Group A. Conclusion: The administration of the broth of 'sirih merah' leaves is able to lower blood sugar levels and to cause hyperplasia of pancreatic Langerhans islets.
\end{abstract}

Keywords: leaves of 'sirih merah', blood sugar level, langerhans island

\begin{abstract}
Abstrak: Daun sirih merah (Piper Crocatum) mengandung senyawa kimia, seperti flavonoid, alkaloid, dan tanin, yang berkhasiat menurunkan kadar gula darah. Penelitian ini bertujuan untuk mengetahui efek pemberian air rebusan daun sirih merah terhadap penurunan kadar gula darah dan gambaran morfologik endokrin pankreas. Penelitan ini merupakan penelitian eksperimental laboratorik yang dilakukan selama lima bulan dengan objek penelitian tikus wistar sebanyak 12 ekor. Tikus dibagi dalam empat, yaitu Kelompok A (kontrol negatif), tikus tidak diberi perlakuan khusus; Kelompok B, tikus diberikan air rebusan daun sirih merah 2,4 ml; Kelompok C tikus diberikan air larutan gula 2,4 ml; dan Kelompok D, tikus diberikan air rebusan daun sirih merah $1,2 \mathrm{ml}$ dan air larutan gula $1,2 \mathrm{ml}$. Hasil penelitian ini menunjukkan bahwa kadar gula darah menurun pada tikus Kelompok B dan D tetapi meningkat pada Kelompok C. Jika dibandingkan dengan Kelompok A, maka ukuran dan jumlah pulau Langerhans pankreas bertambah namun jumlahnya jauh lebih banyak pada Kelompok C (> dari dua kali lipat). Sebaliknya jumlah pulau Langerhans pada Kelompok D relatif hampir sama dengan yang ditemukan pada Kelompok A. Simpulan: Pemberian air rebusan daun sirih merah dapat menurunkan kadar gula darah dan menyebabkan pulau Langerhans pankreas hiperplasia.
\end{abstract}

Kata kunci: Daun sirih merah, kadar gula darah, pulau Langerhans 
Pemanfaatan daun sirih merah untuk kesehatan hanya dilakukan berdasarkan pengalaman yang diperoleh secara turuntemurun. Masyarakat di Jawa memanfaatkan daun sirih merah untuk menyembuhkan penyakit ambeien, keputihan dan obat kumur. ${ }^{1}$ Namun dalam perkembangannya daun ini digunakan untuk mengobati berbagai macam penyakit termasuk diabetes. ${ }^{2}$ Meminum air rebusan daun sirih merah setiap hari dapat menurunkan kadar gula darah sampai pada tingkat yang normal. ${ }^{1,3}$

Daun sirih merah (Piper crocatum) mengandung senyawa aktif seperti flavonoid, alkaloid, terpenoid, tanin, sianogenik, glukosida, isoprenoid, asam amino dan eugenol. Senyawa-senyawa kimia tersebut memiliki sifat antioksidan, antidiabetik, antikanker, antiseptik, antifungal dan antiinflamasi. ${ }^{1}$ Senyawa kimia yang dapat menurunkan kadar gula darah adalah flavonoid, alkaloid, dan tanin. Pada penelitian sebelumnya telah diteliti mengenai mekanisme kerja dari flavonoid dalam aktivasi inhibitor a-glukosidase, salah satu katalisator yang berfungsi mengikat hidrolisis karbohidrat menjadi glukosa (gula sederhana) di usus. Flavonoid merupakan senyawa metabolit sekunder yang terdapat di tanaman hijau. ${ }^{1,4}$

Pankreas merupakan organ yang terletak di retroperitoneal dan terdiri dari tiga segmen utama yaitu kaput, korpus, dan kauda. Kaput terletak pada bagian cekung duodenum, dan kauda menyentuh limpa., Pankreas dibentuk dari 2 sel dasar yang mempunyai fungsi yang berbeda, yaitu selsel eksokrin dan endokrin. Sel-sel eksokrin yang berkelompok-kelompok, disebut sebagai asini, menghasilkan unsur getah pankreas. Sel-sel endokrin atau pulau langerhans menghasilkan sekret endokrin, yaitu insulin dan glukagon yang penting untuk metabolisme kabohidrat. Flavonoid dapat meregenerasi sel beta pankreas, sedangkan tanin memiliki sifat astrigen (terdapat pada permukaan usus halus sehingga menghambat penyerapan gula yang akhirnya akan menurunkan kadar gula dalam darah). ${ }^{7}$
Penelitian ini bertujuan untuk mengetahui efek pemberian air rebusan daun sirih merah terhadap kadar gula darah dan gambaran morfologik endokrin pankreas tikus wistar.

\section{METODE PENELITIAN}

Penelitian ini merupakan penelitian eksperimental laboratorik yang dilakukan di Bagian Patologi Anatomi Fakultas Kedokteran Universitas Sam Ratulangi selama bulan September 2013 - Februari 2014. Subjek penelitian ialah 12 ekor tikus wistar dewasa dengan berat rata-rata 180200 g yang dibagi dalam 4 kelompok(3 ekor tikus perkelompok). Kelompok A (kontrol negatif), tikus hanya diberi pelet standar. Kelompok B, tikus diberi air rebusan daun sirih merah 2,4 ml. Kelompok C, tikus diberi air larutan gula 2,4 ml. Kelompok D, tikus diberi air rebusan daun sirih merah $1,2 \mathrm{ml}$ dan air larutan gula 1,2 ml.

Pemberian air rebusan daun sirih merah dan air larutan gula dilakukan secara oral dengan mengunakan pediatric nasogastrial tube. Air rebusan daun sirih merah dibuat dengan cara merebus 3-4 lembar daun sirih merah dalam $1200 \mathrm{ml}$ air. Air dipanaskan hingga mendidih dan tersisa kurang lebih $600 \mathrm{ml}$. Sebelum pemberian air rebusan daun sirih merah dan larutan gula, tikus dipuasakan selama 6 jam kemudian diukur kadar gula darahnya. Pengukuran gula darah juga dilakukan 1 jam sesudah pemberian air rebusan sirih merah dan larutan gula. Pengukuran kadar gula darah dilakukan setiap 5 hari hingga penelitian selesai.

\section{HASIL PENELITIAN}

Pengukuran gula darah sebelum perlakuan (pra-perlakuan) 1 jam dan sesudah perlakuan (pasca-perlakuan) dapat dilihat pada Tabel 1-4. Rata-rata kadar gula darah pra-perlakuan dari tikustikus kelompok A, B, C dam D secara berurutan ialah 108, 108, 111, dan 100 $\mathrm{mg} / \mathrm{dl}$. Untuk rata-rata kadar gula darah pasca-perlakuan yang diperoleh dari tikus-tikus kelompok B, C, dan D secara 
Jurnal e-Biomedik (eBm), Volume 3, Nomor 3, September-Desember 2015

berturut-turut ialah 94, 127, dan $93 \mathrm{mg} / \mathrm{dl}$. Tampak terjadi penurunan kadar gula darah pasca-perlakuan pada tikus

kelompok B dan D, sebaliknya terjadi peningkatan pada tikus kelompok C.

Tabel 1. Hasil pemeriksaan gula darah puasa kelompok A (kontrol negatif)

\begin{tabular}{lccccccc}
\hline No & Tikus & Hari pertama & Hari ke-6 & Hari ke-11 & Hari ke-16 & Hari ke-21 & $\begin{array}{c}\text { Nilai rata- } \\
\text { rata }\end{array}$ \\
\hline $\mathbf{1}$ & A1 & 114 & - & 115 & 108 & 93 & 108 \\
$\mathbf{2}$ & A2 & 105 & - & 104 & 110 & 116 & 109 \\
$\mathbf{3}$ & A3 & 111 & - & 97 & 97 & 125 & 108 \\
& & & & \multicolumn{2}{c}{ Total rata-rata } & 108 \\
\hline
\end{tabular}

Nel. Naual guid Ualall Ualall IIIy/uı

Tabel 2. Hasil pemeriksaan gula darah puasa kelompok B (diberikan air rebusan daun sirih merah)

\begin{tabular}{|c|c|c|c|c|c|c|c|c|c|c|c|c|c|}
\hline \multirow[t]{2}{*}{ No } & \multirow[t]{2}{*}{ Tikus } & \multicolumn{2}{|c|}{$\begin{array}{c}\text { Hari } \\
\text { pertama }\end{array}$} & \multicolumn{2}{|c|}{ Hari ke-6 } & \multicolumn{2}{|c|}{ Hari ke-11 } & \multicolumn{2}{|c|}{ Hair ke-16 } & \multicolumn{2}{|c|}{ Hari ke-21 } & \multicolumn{2}{|c|}{$\begin{array}{c}\text { Nilai rata- } \\
\text { rata }\end{array}$} \\
\hline & & pra & post & pra & post & pra & post & pra & post & pra & post & pra & post \\
\hline 1 & B1 & 95 & 60 & 99 & 121 & 114 & 111 & 115 & 90 & 106 & 84 & 106 & 93 \\
\hline 2 & B2 & 75 & 58 & 146 & 131 & 131 & 118 & 104 & 64 & 101 & 95 & 112 & 94 \\
\hline 3 & B3 & 101 & 59 & 121 & 118 & 98 & 95 & 110 & 105 & 90 & 96 & 104 & 95 \\
\hline & & & & & & & & & & $1 \mathrm{rat}$ & & 108 & 94 \\
\hline
\end{tabular}

Ket. Kadar gula darah dalam mg/dl

Tabel 3. Hasil pemeriksaan gula darah puasa kelompok C (diberian larutan gula)

\begin{tabular}{|c|c|c|c|c|c|c|c|c|c|c|c|c|c|}
\hline \multirow[t]{2}{*}{ No } & \multirow[t]{2}{*}{ Tikus } & \multicolumn{2}{|c|}{$\begin{array}{c}\text { Hari } \\
\text { pertama }\end{array}$} & \multicolumn{2}{|c|}{ Hari ke-6 } & \multicolumn{2}{|c|}{ Hari ke-11 } & \multicolumn{2}{|c|}{ Hari ke-16 } & \multicolumn{2}{|c|}{ Hari ke-21 } & \multicolumn{2}{|c|}{$\begin{array}{c}\text { Nilai rata- } \\
\text { rata }\end{array}$} \\
\hline & & pra & post & pra & post & pra & post & pra & post & pra & post & pra & post \\
\hline 1 & $\mathrm{C} 1$ & 93 & 148 & 93 & 151 & 121 & 120 & 116 & 106 & 121 & 98 & 110 & 125 \\
\hline 2 & $\mathrm{C} 2$ & 98 & 138 & 151 & 134 & 115 & 118 & 97 & 118 & 95 & 122 & 115 & 126 \\
\hline \multirow[t]{2}{*}{3} & $\mathrm{C} 3$ & 96 & 161 & 131 & 138 & 93 & 108 & 100 & 160 & 116 & 88 & 109 & 131 \\
\hline & & & & & & & & \multicolumn{4}{|c|}{ rata-rata } & 111 & 127 \\
\hline
\end{tabular}

Ket. Kadar gula darah dalam mg/dl

Tabel 4. Hasil pemeriksaan gula darah puasa kelompok D (diberikan air rebusan daun sirih merah + larutan gula)

\begin{tabular}{|c|c|c|c|c|c|c|c|c|c|c|c|c|c|}
\hline \multirow[t]{2}{*}{ No } & \multirow[t]{2}{*}{ Tikus } & \multicolumn{2}{|c|}{$\begin{array}{c}\text { Hari } \\
\text { pertama }\end{array}$} & \multicolumn{2}{|c|}{ Hari ke-6 } & \multicolumn{2}{|c|}{ Hari ke-11 } & \multicolumn{2}{|c|}{ Hari ke-16 } & \multicolumn{2}{|c|}{ Hari ke-21 } & \multicolumn{2}{|c|}{$\begin{array}{c}\text { Nilai rata- } \\
\text { rata }\end{array}$} \\
\hline & & pra & post & pra & post & pra & post & pra & post & pra & post & pra & post \\
\hline 1 & D1 & 115 & 108 & 107 & 89 & 131 & 125 & 85 & 94 & $X$ & X & 88 & 83 \\
\hline 2 & D2 & 103 & 89 & 148 & 134 & 130 & 95 & 84 & 69 & 88 & 93 & 111 & 96 \\
\hline 3 & D3 & 104 & 98 & 105 & 138 & 123 & 94 & 85 & 81 & 87 & 77 & 101 & 98 \\
\hline & & & & & & & & & \multicolumn{3}{|c|}{ Total rata-rata } & 100 & 93 \\
\hline
\end{tabular}

Ket. Kadar gula darah dalam mg/dl 


\section{Gambaran Mikroskopik Pankreas}

Pada tikus kelompok A (kontrol negatif) didapatkan gambaran mikroskopik pankreas yang normal. Sediaan pankreas ini terdiri dari kira-kira 80\% kelenjar eksokrin (exocrine secretory acini) dan sisanya kelenjar endokrin yaitu pulau Langerhans (Gambar 1).

Pada tikus kelompok B (diberikan air rebusan daun sirih merah) didapatkan gambaran mikroskopik pankreas dengan beberapa pulau Langerhans yang membesar dan beberapa sel yang sitoplasmanya berwarna merah muda sebagai tanda terjadinya hiperplasia sel (Gambar 2).

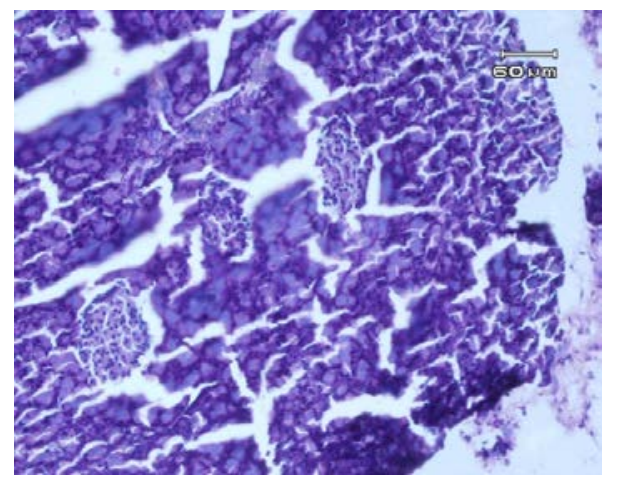

Gambar 1. Gambaran mikroskopik pankreas tikus wistar kelompok A (kontrol negatif). Tampak kelenjar eksokrin lebih dominan daripada pulau Langerhans. Pembesaran 10x20

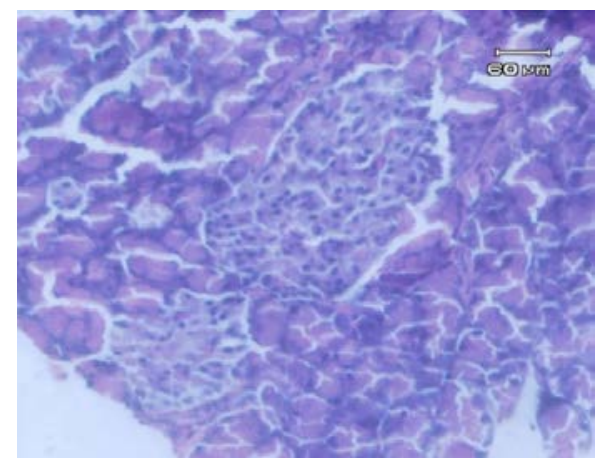

Gambar 3. Gambaran mikroskopik pankreas tikus wistar kelompok C (diberikan larutan gula). Tampak kelenjar eksokrin dan pulau Langerhans yang membesar. Pembesaran 10x20
Pada tikus kelompok C (diberikan larutan gula) didapatkan gambaran mikroskopik pankreas dengan beberapa pulau Langerhans yang membesar dan adanya bercak-bercak berwarna merah muda atau terjadi hiperplasia sel (Gambar 3).

Pada tikus kelompok D (diberikan air rebusan daun sirih merah dan larutan gula) didapatkan gambaran mikroskopik pankreas dengan beberapa pulau Langerhans yang mengecil atau membesar dan adanya bercak-bercak berwarna merah muda sebagai tanda terjadinya hiperplasia sel (Gambar 4). Perbandingan ukuran pulau Langerhans dapat dilihat pada Gambar 5.

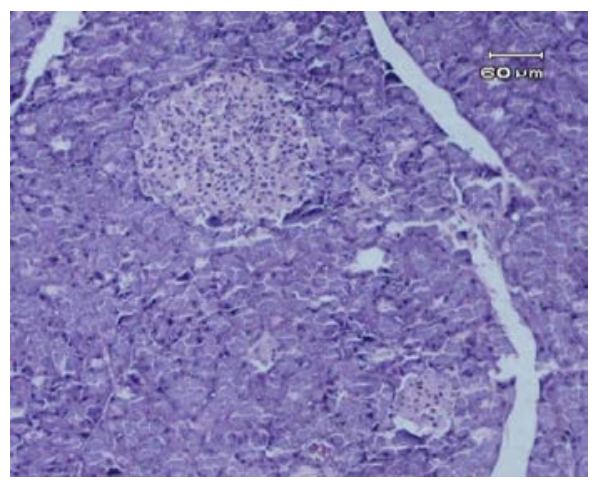

Gambar 2. Gambaran mikroskopik pankreas tikus wistar kelompok B (larutan sirih merah). Tampak kelenjar eksokrin, dan pulau Langerhans yang membesar. Pembesaran 10x20

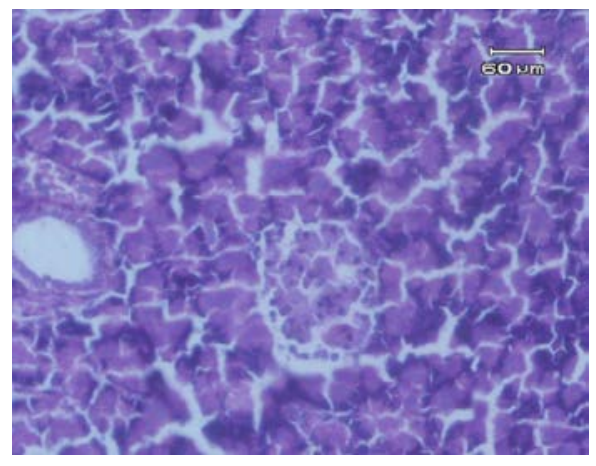

Gambar 4. Gambaran mikroskopik pankreas tikus wistar kelompok D (diberikan rebusan daun sirih merah dan larutan gula). Tampak kelenjar eksokrin dan pulau Langerhans yang membesar. Pembesaran 10x20 
Jumlah dan Ukuran Pulau Langerhans

Pada pengamatan secara mikroskopik didapat hasil sebagai berikut: pada kelompok kontrol A3 didapatkan jumlah pulau Langerhans 7 pulau; pada kelompok B1: 12 pulau; B2: 11 pulau; pada kelompok
C didapatkan C1 18 pulau, C2 20 pulau; dan pada kelompok $\mathrm{D}$ yaitu dengan pemberian air rebusan daun sirih merah dan larutan gula didapatkan D1 6 pulau, dan D2 4 pulau (Tabel 5).

Tabel 5. Hasil perhitungan jumlah pulau Langerhans

\begin{tabular}{cccc}
\hline No & Kelompok & Jumlah Pulau Langerhans & keterangan \\
\hline $\mathbf{1}$ & A3 & 7 & $\begin{array}{c}\text { Kelompok } \\
\text { kontrol }\end{array}$ \\
$\mathbf{2}$ & B1 & 12 & $\begin{array}{c}\text { Kelompok } \\
\text { perlakuan }\end{array}$ \\
$\mathbf{3}$ & B2 & 11 & $\begin{array}{l}\text { Kelompok } \\
\text { perlakuan }\end{array}$ \\
$\mathbf{4}$ & C1 & & $\begin{array}{l}\text { Kelompok } \\
\text { perlakuan }\end{array}$ \\
$\mathbf{5}$ & C2 & 18 & $\begin{array}{l}\text { Kelompok } \\
\text { perlakuan } \\
\text { Kelompok } \\
\text { perlakuan }\end{array}$ \\
$\mathbf{6}$ & D1 & 20 & $\begin{array}{l}\text { Kelompok } \\
\text { perlakuan }\end{array}$ \\
\hline $\mathbf{7}$ & D2 & 6 & \\
\hline
\end{tabular}
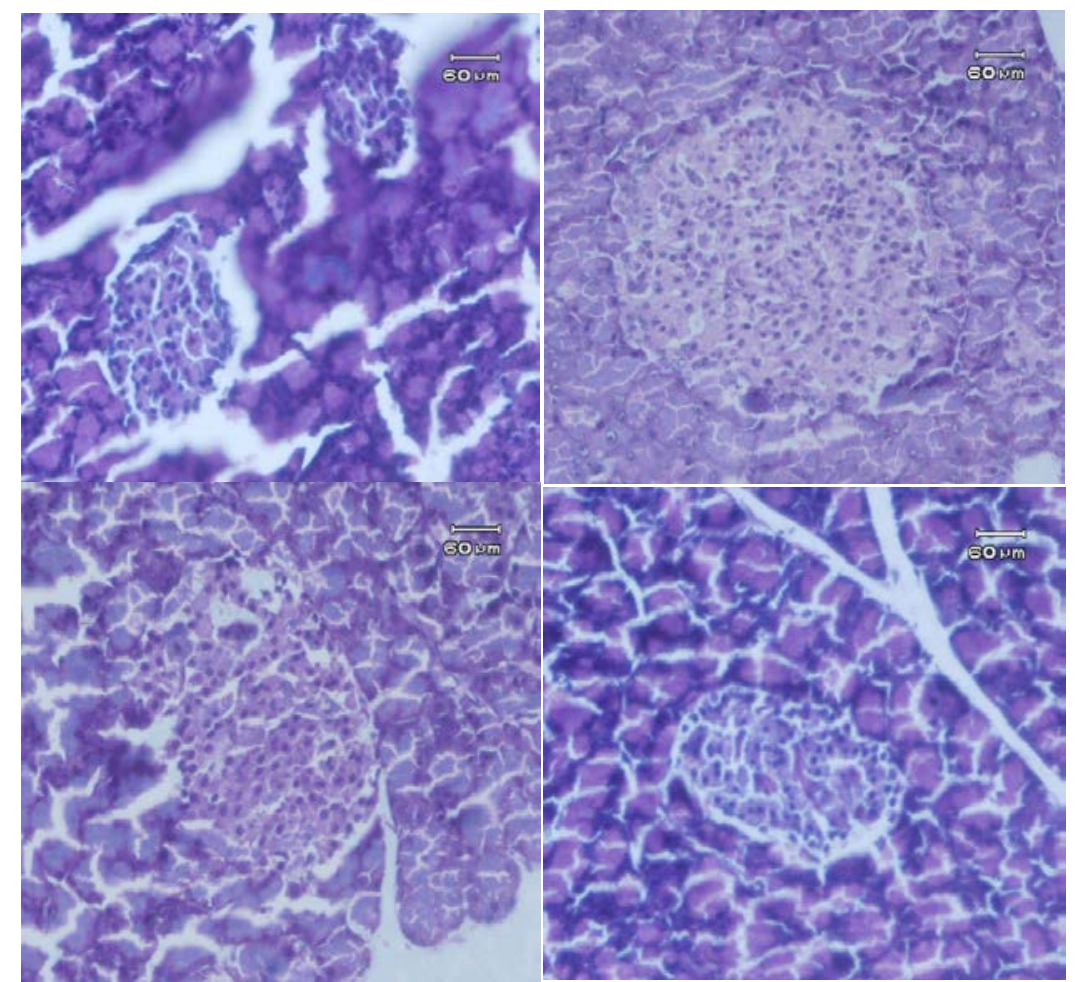

Gambar 5. Perbandingan ukuran pulau Langerhans pankreas (pembesaran 200x). A) Pulau Langerhans dengan ukuran panjang 2cm dan lebar 1,3cm (kelompok A); B) Pulau Langerhans panjang 3,1cm dan lebar 3cm (kelompok B); C) Pulau Lanngerhans panjang 2,7cm dan lebar 2cm (kelompok C); dan D) Pulau Langerhans panjang 1,3cm dan lebarnya $2 \mathrm{~cm}$ (kelompok D). 


\section{BAHASAN}

Daun sirih merah merupakan salah satu tanaman yang berkhasiat menurunkan kadar gula darah. Daun sirih merah mengandung senyawa kimia yang dapat menurunkan kadar gula darah yaitu flavonoid, alkaloid, dan tanin. Pada penelitian lain telah diteliti mengenai mekanisme cara kerja flavonoid yang berperan untuk aktivasi inhibitor aglukosidase sebagai salah satu katalisator yang berfungsi mengikat hidrolisis karbohidrat menjadi glukosa (gula sederhana) diusus. ${ }^{1}$

Pada penelitian ini pemberian rebusan daun sirih merah secara tunggal (kelompok B) dan bersama-sama dengan larutan gula (kelompok D) keduanya menunjukkan penurunan kadar gula darah. Penurunan kadar gula darah pada kelompok B dan D tersebut dapat disebabkan karena senyawa flavonoid, alkaloid, dan tanin yang terdapat dalam daun sirih merah. ${ }^{5}$

Demikian juga dengan ukuran dan jumlah pulau Langerhans yang bertambah pada tikus yang diberi air rebusan daun sirih merah. Flavonoid dapat meregenerasi sel beta pankreas, dan kandungan tanin memiliki sifat astrigen yang dapat menghambat penyerapan gula pada permukaan usus halus sehingga dengan demikian dapat menurunkan kadar gula darah. ${ }^{8}$ Bertambahnya pulau Langerhans pada pemberian rebusan daun sirih merah belum dapat dijelaskan.

\section{SIMPULAN}

Air rebusan daun sirih merah dapat menurunkan kadar gula darah dan menyebabkan hiperplasia pulau Langerhans pankreas tikus wistar.

\section{DAFTAR PUSTAKA}

1. Manoy F. Sirih Merah Sebagai Tanaman Obat Multifungsi. Depok: Warta Puslitbangbun, 2007; p. 22-7.

2. Utami P, Puspaningtyas ED. The miracle of Herbs. Jakarta: Agromedia Pustaka, 2013; p. 169-75.

3. Mardiana L. Daun ajaib tumpas penyakit. Jakarta: Penebar Swadaya, 2012; p.1649.

4. Hidayat RS, Napitupulo RM. Kitab Tumbuhan Obat. Jakarta: AgriFlo, 2015; p. 364-6.

5. Utami P. Buku pintar tanaman obat. Jakarta: Agromedia Pustaka, 2008; p. 225-8.

6. Linseth GN. Gangguan Hati, Kandung Empedu, dan Pankreas. In: Hartanto H, Wulansari P, Susi N, Mahanani DA, editors. Buku Ajar Patofisiologi (6th ed). Jakarta: EGC, 2003; p. 477-8.

7. Kumar V, Crawford MJ, Clare-Salzler JM. Pankreas. In : Hartanto $\mathrm{H}$, Darmaniah N, Wulandari N, editors. Buku Ajar Patologi Robbins 2nd ed). Jakarta: EGC, 2004; p. 711-34.

8. Permata DA. Potensi Rebusan Sirih Merah (Piper Crocatum) Terhadap Perbaikan Pankreas Tikus Wistar Hiperglikemi [Tesis]. Bogor: IPB, 2006; p. 3-4. 